9-1990

\title{
Professional Decisions and Ethical Values in Medical and Law Students
}

\author{
Robert L. Schwartz \\ University of New Mexico - School of Law \\ Agnes G. Rezler \\ Pamela Lambert \\ S. Scott Obenshain \\ Joan Mclver Gibson
}

See next page for additional authors

Follow this and additional works at: https://digitalrepository.unm.edu/law_facultyscholarship

Part of the Health Law and Policy Commons

\section{Recommended Citation}

Robert L. Schwartz, Agnes G. Rezler, Pamela Lambert, S. Scott Obenshain, Joan Mclver Gibson \& David A. Bennahum, Professional Decisions and Ethical Values in Medical and Law Students, 65 Academic Medicine 531 (1990).

Available at: https://digitalrepository.unm.edu/law_facultyscholarship/740

This Article is brought to you for free and open access by the UNM School of Law at UNM Digital Repository. It has been accepted for inclusion in Faculty Scholarship by an authorized administrator of UNM Digital Repository. For more information, please contact amywinter@unm.edu, Isloane@salud.unm.edu,sarahrk@unm.edu.

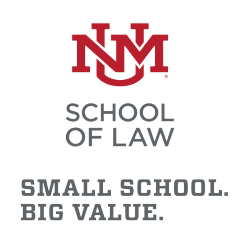

BIG VALUE. 


\section{Authors}

Robert L. Schwartz, Agnes G. Rezler, Pamela Lambert, S. Scott Obenshain, Joan Mclver Gibson, and David A. Bennahum 


\title{
Professional Decisions and Ethical Values in Medical and Law Students
}

\author{
AGNES G. REZLER, PAMELA LAMBERT, S. SCOTT OBENSHAIN, ROBERT L. SCHWARTZ, JOAN MCIVER GIBSON, \\ and DAVID A. BENNAHUM
}

The purpose of this project is to evaluate and compare the values used by medical and law students when dealing with ethical dilemmas in the professional practice of law and medicine. It is assumed that conflict between doctors and lawyers often arises out of the different values that members of each profession apply to similar dilemmas.

Both medical and law schools have offered a variety of courses in ethics for some time. Despite these efforts the most important questions remain unanswered - and largely unasked. Which ethical values govern the actions of doctors and medical students? Of lawyers and law students? What is the relationship between the actions and underlying values of law and medical students in situations presenting ethical dilemmas? While much has been written about professional ethics, little is known about the role of values in professional decision-making and the degree to which different values create conflicts among professionals.

This study is designed to (1) identify the values used by medical and law students when they have to resolve ethical dilemmas; (2) compare the values within and between these 2 types of students; and (3) discover the extent to which their values change during the course of professional training. This paper deals only with the first 2 issues.

Rest ${ }^{1}$ published a major synthesis of the literature describing 4 psychological processes underlying ethical behavior. The $4 \mathrm{com}$ ponents are (1) to be sensitive to the needs of others; (2) to engage in moral reasoning when a course of action is formulated; (3) to decide which values are most important in a situation containing a moral dilemma; and (4) to execute and implement a plan of action.

Sensitivity to the needs of others, or empathy, can be assessed by several tests. ${ }^{2-4}$ The latter, called the Dental Ethical Sensitivity Test, focuses on the recognition- of ethical issues in professional encounters. All of the above tests speak only to Rest's first component.

Moral reasoning, the second component, has been evaluated by the Defining Issues Test, ${ }^{5}$ which is based on Kohlberg's 6 stages of moral development. ${ }^{6}$ The DIT is a written test that presents 6 dilemmas to be resolved. Sheehan's ${ }^{7}$ performance test delves into components 1,2 , and 4: ethical sensitivity, moral reasoning, and the implementation of a plan of action. He uses a medical interview with simulated patients to assess the above components. Rest's third component, to decide which values are most important in a moral dilemma, has not been measured so far.

\section{Method}

Assessment of Ethical Values. The Professional Decisions and Values Test (PDV) was developed because none of the available tests suited the purpose of this study. The PDV contains 10 brief vignettes: 4 include medical problems; 4 present legal problems; 2 are in the context of professional education. For each vignette there are 3 alternative actions to choose from and 7 alternative reasons to justify the action selected. Each of the reasons represents 1 of 7 values most commonly used to resolve ethical dilemmas: autonomy, beneficence, confidentiality, harm avoid- ance, justice, professional responsibility, and truth telling. One sample item follows:

\section{CASE 1}

You are a family physician and your patients include the Bowser family. Mrs. Bowser was recently in for a Pap smear and a gonorrhea culture. The Pap smear was normal but the culture was positive. You inform the patient about the positive culture and tell her that you have to report it to the Health Department. At the same time you reassure her that gonorrhea can easily be treated with antibiotics, which are prescribed for her. Mrs. Bowser's major concern is that her husband not find out about the test results.

What would you do? (Circle only 1 answer.)

1. Urge Mrs. Bowser to tell her husband, but agree to respect her privacy whatever she decides.

2. Ask Mrs. Bowser to schedule an office visit for her husband by a certain date, after which you would call him yourself.

3. Contact the husband right away to inform him.

If you disagree with all 3 actions, propose another action. Circle the 1 (or 2) most important reason(s) that justify your action. [The value represented by each statement is in brackets. It is NOT shown on the test.]

a. Mr. Bowser should be protected from infection [Harm Avoidance].

b. As a physician you should not divulge your patients' confidences [Confidentiality].

c. Mrs. Bowser's wishes in the matter should be respected [Autonomy].

d. The physician's job is to promote the well being of all members of the family [Beneficence].

e. Physicians have a professional duty to consider the public health impact of individual patient decisions [Professional Responsibility].

f. You are obliged to tell Mr. Bowser the truth about his wife's condition that could affect him directly [Truth Telling].

g. It is unfair to place Mr. Bowser at risk simply to protect his wife's privacy [Justice].

Fixed answers are listed with each item to permit objective scoring and to shorten testing time. But respondents are also given the opportunity to write their own answers if none of the fixed answers appeals to them.

Value Scores. Each reason selected by a respondent contributes to a value score. One or 2 reasons may be selected to justify a decision. Seven scores are computed for each individual, 1 for each value. A higher score does not indicate a better score, since this is not an achievement test. A higher score indicates stronger commitment to a given value.

Actions are not scored, but choices are tabulated for each action to assess preferred choices and consensus within the group.

In 1988 the authors conducted a pilot study with a preliminary version of the PDV with 68 medical and 88 law students (over $90 \%$ of each class). Data from the pilot study contributed to estimating the reliability and validity of the PDV.

Validity. Content validity was built into the PDV by reviewing the literature and the content of courses in medical and legal ethics to select 7 values that were relevant to both professions. These 7 values were translated into reasons to fit the actions in each case. Three independent judges matched each reason with 1 
of the 7 values. Unless 2 of the 3 judges agreed, the reason was revised or replaced. Construct validity was estimated by correlating each value with every other value for both the 1988 and 1989 samples. Over $90 \%$ of the correlations were not significant, indicating that the 7 values are independent and that assigning 7 scores to each person is justified. Another indication of construct validity is that group differences in value preferences correspond to professional expectations. Validity data are needed on the relationship between value scores and measures of professional behaviors.

Reliability. Two kinds of reliability were calculated: (1) internal consistency and (2) test-retest. Internal consistency was estimated by Alpha; it ranged from 0 to .23, indicating that values are specific to situations and dilemmas. Confidentiality may be quite important in one case but may not influence action in another case.

Data for test-retest reliability came from 39 third-year students who were retested on Form II after a 5 month interval. Percent of agreement between test-retest responses was calculated for actions as well as for values. Agreement for actions ranged from 56 to $92 \%$ for 8 cases. Agreement within values ranged from 67 to $80 \%$. Test-retest reliability calculations will be repeated with scores from the revised test, upon which the results are based.

Sample and Data Collection. The entering classes in the medical and law school comprised the sample. The medical class contained 77 students ( 45 men and 32 women); there were 92 students in the law class ( 49 men and 43 women). The PDV was administered during orientation week to both classes as a "captive audience"; the response rate was $100 \%$. To protect student anonymity and to encourage honest answers, students were asked to identify themselves only by their birth date, gender, and profession.

Data Analysis. The data were analyzed to study (1) value differences between medical and law students, (2) value differences between men and women in the same profession, and (3) differences associated with the content of the cases. Mean value scores were computed for all 7 values and compared across professions and across genders by the $t$-test.

The proportion of students choosing all 7 values in each case was calculated to identify which values play a prominent role in different cases. Within each case the choice of a given value was compared across 4 groups: medicine male (MM); medicine female (MF), law male (LM), law female (LF). The chi-square statistic was used for these comparisons to highlight group prefence or selected values.

\section{Results}

Only major findings are listed due to the limitations in the length of this paper.

1. Medical and law students differ on 3 values:

(a) beneficence (higher in medical students, $\bar{X}=1.60$ vs. $1.04, t=2.40, p=.02$ )

(b) professional responsibility (higher in law students, $\overline{\mathrm{X}}=$ 3.42 vs. $2.12, t=3.08, p=.003$ );

(c) harm avoidance (higher in medical students, $\overline{\mathrm{X}}=2.93$ vs. $2.04, t=2.82, p=.006$ )

2. There are no significant gender differences across all cases. Gender differences do occur, however, in relation to particular cases; for example, in Case 8 more medical women than men depend on justice to grant an abortion to a young, single woman.

3. The content of a case influences which values are selected by which group. For example, in Case 3 more medical students are willing to grant autonomy to a terminal cancer patient. More law students invoke beneficence to keep the patient alive against her will.
4. The 7 value scores measure independent dimensions with 5 exceptions. Five of 22 correlations are statistically significant but below .25. Professional responsibility is negatively correlated with autonomy, confidentiality, and justice. Truth is positively correlated with beneficence and negatively with autonomy.

\section{Discussion and Implications}

Two limitations should be kept in mind regarding the findings. First the PDV is a new test and requires further validation. Second, entering classes from 2 professional schools represent only these 2 schools, and the results may not apply to other schools.

Overall, the ethical values of medical and law students are more similar than different. Significant differences were noted on only 3 values: beneficence, professional responsibility, and harm avoidance. It may be expected that medical students should feel more strongly about harm avoidance, particularly when they are novices. Similarly one would expect medical students to score higher on beneficence. Law students, on the other hand, rely more often on professional responsibility to justify their actions.

Several value differences occur only in relation to certain cases. The interaction of case content, profession, gender, and values needs to be more fully explored.

The results of this study could contribute to instruction as well as evaluation. Administering the PDV prior to a course would inform the teacher which ethical dilemmas elicit diversified and/or inappropriate actions and reasons. These dilemmas could be discussed to permit students to air their concerns and to check their solutions against their peers. Students could also be shown a sample case and asked to generate similar cases in the same format. Writing the actions and the reasons would help to clarify "fuzzy" thinking and stimulate problem solving.

The PDV could also be used with professionals in law and medicine to elucidate areas of strong agreement and disagreement. Value conflicts could be reduced when the basis for the differences are better understood.

Finally, the PDV could serve as a standardized evaluation method to assess the outcomes of instruction. Since there are multiple correct answers it is better suited for diagnostic testing than for grading or certification. As a diagnostic test it could provide feedback to both teachers and students about the outcome of instruction.

This study was supported jointly by the Fund for the Improvement of Post-second. ary Education (Grant \#00851018), the UNM Office of Undergraduate Medical Education, and the UNM Research Committee.

Correspondence: Agnes G. Rezler, Ph. D., University of New Mexico, Basic Medical Science Bldg., P.O. Box 708, Albuquerque NM 87131.

\section{References}

1. Rest, J. R. Morality. In Carmichael's Manual of Child Psychology, P. H. Mussen, ed. New York: Wiley, 1983.

2. Hulka, B. S., et al. A Method for Measuring Physician Awareness of Patient Concerns. HSMHA Health Report 86(1981):741-751.

3. Jordan, A., et al. Psychological, Cognitive and Affective Correlates of Two Experimental Examinations of Medical Student Interpersonal Skills. Paper presented at the Eastern Educational Research As8ociation meeting, New York, 1980.

4. Bebeau, M. J., Rest, J. R., and Yamoor, C. M. Measuring Dental Students' Ethical Sensitivity. J. Dental Educ. 49(1985):225-235.

5. Rest, J. R. Development in Judging Moral Issues. Minneapolis, Minnesota: University of Minnesota Press, 1979.

6. Kohlberg, L. The Philosophy of Moral Development: Moral Stages and the Ideal of Justice. San Francisco, California: Harper and Row, 1981.

7. Sheehan, T. J., et al. Improving Physicians' Skills in Managing Morally Problematic Cases. Paper presented at the American Educational Research Association meeting, Washington, D.C., 1987. 